\title{
A Contrastive Study of Chinese and British English Request Strategies Based on Open Role- play
}

\author{
Xiuping Han \\ BinZhou Medical University, YanTai, China
}

\begin{abstract}
This study investigates the similarities and differences in request strategies used by native speakers of British English and Mandarin Chinese. The method of a non-prescriptive open role-play is used as the instrument of data collection. After the analysis of the data is conducted, the findings of the study is presented and discussed, including the realization of three main requests strategies. Besides, this paper also focuses on how request strategies interact with the two social variables of power and distance.
\end{abstract}

Index Terms - contrastive study, open role-play, speech act, request strategy

\section{INTRODUCTION}

In everyday interactions, people constantly create utterances to achieve certain communicative intentions. These interactional goals are represented by particular speech acts such as requests, apologies, compliments, refusals, disagreements, and the like. Among these, the speech act of request has fascinated linguists working on cross-cultural and cross-linguistic studies.

A speech act of request is a prominent event in daily interactions, one in which the speaker usually manipulates appropriate linguistic forms to make requests according to certain situations. People produce requests for various reasons in everyday interactions, either to obtain information or certain action, to seek support, or to acquire assistance from others; however, the way requests are presented varies from one speech community to another. In a request the speaker to a greater or lesser extent imposes on the addressee hence there is a need to put politeness strategies into action in order to mitigate the imposition, in other words, to soften what the addressee might regard as an impingement on his/her freedom of action (Blum-Kulka, 1984). Thus speakers tend to employ a variety of strategies to try to make sure their requests will be granted. Such strategies will inevitably reflect the expression of politeness.

Given that requests are impositives, a speaker in making a request takes into consideration situational, social, and cultural factors, choosing appropriate linguistic forms to accomplish a speech act of request so as to maintain or establish a harmonious relationship with the hearer in such a situation. A study of request strategies allows us to take a closer look at politeness, cultural values, and other social aspects of a particular community.

Although a lot of work has been carried out on politeness phenomena, mainly through the analysis of the realization patterns of speech acts in a number of languages, there has been little work on East Asian languages, and there is less work on the contrastive analysis of particular kinds of speech acts as realized in Mandarin Chinese and British English. This study, as an attempt to address cross-linguistic and cross-cultural strategies employed in the speech act of request between a western language and an East Asian language, will hopefully provide some insights into politeness and speech acts.

\section{A. Purpose of the Study}

The main purpose of this study is to explore the politeness of request speech acts by investigating the patterns used by native speakers of Mandarin Chinese and British English under the influence of some social factors, such as social, cultural, and situational factors which produce sensitivity in both interlocutors. And the term ---'native speaker' refers to the participants in this research who can speak Mandarin Chinese or British English as their mother tongue.

Social variables, such as power, status and familiarity are indispensable for the realization of request speech acts, and these factors also determine the effects of the patterns of requests used by people from different cultures. (Brown and Levinson, 1987). By identifying the specific influences of social factors on request speech act, this study also try to analyze the speech acts in terms of power status and familiarity.

Specifically, this study focus on the choice of patterns of request strategies, including the choice of head acts, internal modifications, and external modifications, and on how request strategies interact with the two social variables of power and distance.

\section{B. Methodologies for Data Collection}

Written questionnaire is one of the most commonly used data collection method in the study of cross-cultural communication or inter-language pragmatics to obtain targeted speech acts. It has been employed by many researchers 
to examine the performance of the request speech act. But it has been pointed out by many including Blum-Kulka, Blum-Kulka and Olshtain, Hong, and Lee-Wong that the use of questionnaires also has some limitations. Imagining which speech act they would use in a given situation is rather difficult for participants, so that written responses may not actually correspond with oral performance they use in real life. Furthermore, they may not reveal the actual pragmatic features of spoken interactions.

Role-play has been used as an effective way of collecting oral data in this study of inter-cultural and cross-linguistic pragmatics. Responses in role-plays were recorded by audio taping, and then are transcribed. They allow researchers to obtain more interactive data as weel as providing sufficient time of responding.

Role-play includes two forms --- closed role-play and open role-play. In a closed role-play, participants respond verbally to a given situation without a reply from others. Open role-play allows participants to interact with each other and thus offers more conversational features, such as the process of negotiation, hesitation, the sequences of an action, etc. Open role-play also allows an examination of the sequences of negotiation which helps in the realization of complete forms of request interactions.

\section{Design of the Role-play Situations}

In order to examine the influence of social variables on the speech act of requesting, nine request situations for roleplays were designed, in which situations varied with the three social variables of distance, power and imposition. The power variable has three levels: +Power (the addressee has a higher power than the speaker), =Power (having parallel status), and -Power (the addressee has a lower power than the speaker). There are various types of power, such as age, gender, physical strength, or institutionalized roles (Brown and Gilman, 1960). The variable of social distance also has three levels: $+\mathrm{D}$ (the interlocutors are strangers), =D (the interlocutors are acquaintances), and $-\mathrm{D}$ (the interlocutors know each other very well). Finally, the ranking of imposition has two levels: $+R$ (a high extent of imposition) and $-R$ (a low extent of imposition). This study focuses on $+\mathrm{R}$ because requests made in all nine situations have a high degree of imposition. Because of this, elaborate request strategies were likely to be elicited. People tend to employ more strategies in situations that have a high degree of imposition. They will also think more and even make careful planning before they utter their request in order to make their requests approved. All the nine role-play situations are listed in Appendix. Table 1 shows the classification of role-plays according to contextual and social variables in the nine roleplay situations.

TABLE . 1

CLASSIFICATION OF ROLE-PLAYS ACCORDING TO CONTEXTUAL AND SOCIAL VARIABLES

\begin{tabular}{|c|c|c|c|}
\hline Situations & Social power & Social distance & Ranking of imposition \\
\hline R1 (borrow money) & $+\mathrm{P}$ & $+\mathrm{D}$ & $+\mathrm{R}$ \\
\hline R2 (borrow car) & $+\mathrm{P}$ & $-\mathrm{D}$ & $+\mathrm{R}$ \\
\hline R3 (borrow computer) & $-\mathrm{P}$ & $+\mathrm{D}$ & $+\mathrm{R}$ \\
\hline R4 (ask to stay in one's house) & $=\mathrm{P}$ & $-\mathrm{D}$ & $+\mathrm{R}$ \\
\hline R5 ( ask a neighbor for help) & $=\mathrm{P}$ & $+\mathrm{D}$ & $+\mathrm{R}$ \\
\hline R6 (cancel holiday) & $-\mathrm{P}$ & $-\mathrm{D}$ & $+\mathrm{R}$ \\
\hline R7 (change jobs) & $+\mathrm{P}$ & $=\mathrm{D}$ & $+\mathrm{R}$ \\
\hline R8 (ask an employee for help & $-\mathrm{P}$ & $=\mathrm{D}$ & $+\mathrm{R}$ \\
\hline R9 (ask a colleague to treat a meal) & $=\mathrm{P}$ & $=\mathrm{D}$ & $+\mathrm{R}$ \\
\hline
\end{tabular}

To sum up, the use of open role-play as the instrument of data collection has the benefit of providing us with a controlled context yet one which allows us to examine speech act behavior in its discourse context; in which the social variables believed to be involved in the performance of the speech acts can be manipulated and allowing for 'real' interaction and a limited amount of 'spontaneity'.

\section{The Subjects}

The participants including 16 native speakers of British English ( 8 males and 8 females) and 20 native speakers of Chinese (11 males and 9 females) were matched in pairs in random in each situation, and their conversations were recorded respectively for further analysis. Most of the participants were between 18 and 35 years of age.

\section{E. Coding for the Study}

A request is comprised of head acts, internal modifications (lexical/syntactic modifications), and external modifications (supportive moves) according to Blum- Kulka. This study also makes use of CCSARP methodology that is widely used in the field of request studies to analyze the data.

Head acts are usually classified into three main levels in relation to the degree of directness; each level is further classified into sub-categories. 1) Direct head acts comprise mood derivable, performatives, obligation statements, and want statements; 2) Conventionally indirect head acts are made up of suggestory formulae and the query preparatory; (3) Non-conventionally indirect head acts consist of strong hints and mild hints. 
TABLE 2

\begin{tabular}{|c|c|c|}
\hline \multicolumn{3}{|c|}{ HEAD ACTS IN ENGLISH AND CHINESE REQUESTS } \\
\hline Directness levels & Strategies & Descriptions and examples \\
\hline \multirow{12}{*}{$\begin{array}{l}\text { Level 1: Direct strategies } \\
\text { (Impositives) }\end{array}$} & Mood derivable & $\begin{array}{l}\text { The grammatical mood (imperative) used in this form is conventionally } \\
\text { regarded as a request. }\end{array}$ \\
\hline & & Chinese:帮我倒杯水。（Give me a glass of water.） \\
\hline & & English: Pass me the salt, please. \\
\hline & Performative & $\begin{array}{l}\text { The speaker conveys the illocutionary intent by using a relevant } \\
\text { illocutionary verb, making the utterance an order, a plea or begging. }\end{array}$ \\
\hline & & Chinese:我求你借我点钱。(I beg you to lend me some money.) \\
\hline & & English: I'd like to ask you to give me one more chance. \\
\hline & $\begin{array}{l}\text { Obligation } \\
\text { statement }\end{array}$ & $\begin{array}{l}\text { The speaker conveys the illocutionary intent by stating moral obligation } \\
\text { directly. }\end{array}$ \\
\hline & & Chinese:你得/该帮我一把。（You should give me a hand.） \\
\hline & & English: You must come back early. \\
\hline & Want statement & The speaker conveys the illocutionary intent by asserting a particular \\
\hline & & Chinese: 我想请你帮个忙。（I want to ask you a favor.) \\
\hline & & English: I need a dictionary. \\
\hline \multirow{7}{*}{$\begin{array}{l}\text { Level 2: Conventionally } \\
\text { indirect strategies }\end{array}$} & Suggestory formula & The speaker conveys the illocutionary intent expressed as a suggestion. \\
\hline & & Chinese:今晚去跳舞怎么样？（How about going dancing tonight?） \\
\hline & & English: Why don't you have some more? \\
\hline & Query preparatory & The utterance contains a preparatory question referring to the feasibility \\
\hline & & $\begin{array}{l}\text { of the request, including asking the hearer's ability, willingness, } \\
\text { permission, possibility or convenience to perform the act. }\end{array}$ \\
\hline & & Chinese:你能帮我个忙吗? (Can you do me a favor?) \\
\hline & & English: Would you mind closing the door? \\
\hline \multirow{8}{*}{$\begin{array}{l}\text { Level 3: Non } \\
\text {-conventionally } \\
\text { indirect strategies (Hints) }\end{array}$} & Strong hint & $\begin{array}{l}\text { While the illocutionary intent is not expressed overtly, the speaker } \\
\text { provides strong clues for the hearer to construe the request. }\end{array}$ \\
\hline & & Chinese:这个房间很热。（This room is very hot.） \\
\hline & & English: I'm rather hungry. \\
\hline & Mild hint & The speaker conveys the illocutionary intent by providing less strong \\
\hline & & clues, but it is still interpretable as a request with the help of context. \\
\hline & & Greater inference is required on the part of the hearer. \\
\hline & & Chinese: 你忙吗？（Are you busy?） \\
\hline & & English: May I speak to you? \\
\hline
\end{tabular}

\section{THE FINDINGS}

The analysis of the data resulting from the open role-play is based upon an independent evaluation of each response according to a number of dimensions. The strategy types are based on three levels of directness and impact: direct level (impositives), conventionally indirect and non-conventionally indirect level. We will start this section by presenting a percentage distribution of the main request strategy types in British English (BE) and Chinese $(\mathrm{CH})$ across all nine situations. The analysis of the data will be presented in terms of request strategies and not by situations since the coding scheme for this study is based upon three levels of directness and, as it will be recalled, the three different levels of directness have been interpreted as strategies. The distribution of the request strategies reveals a high degree of crosscultural agreement. There is a marked preference for conventional indirectness across most situations in both languages. 
TABLE 3

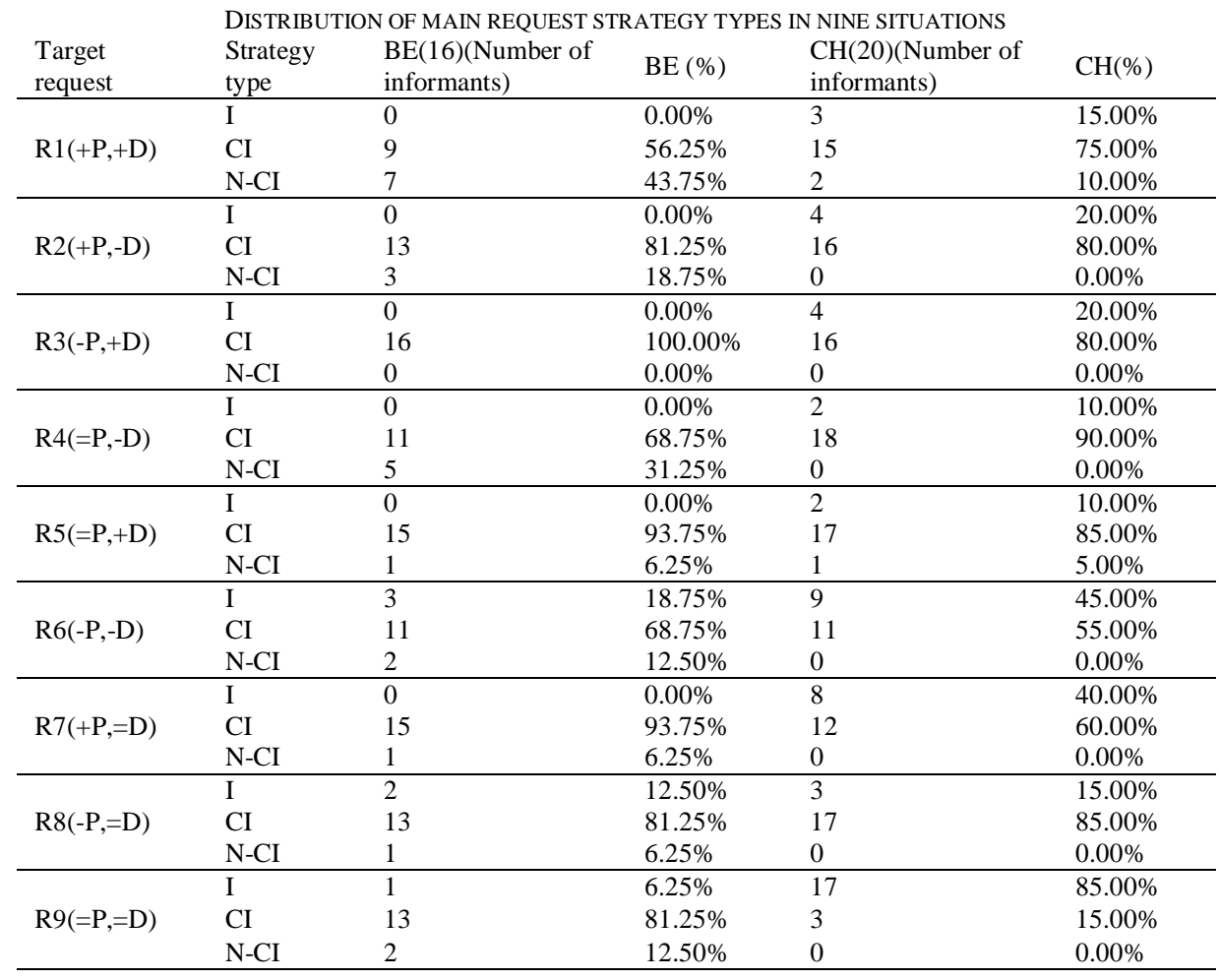

R:Request open role-play situations; I: Impositives; CI:Conventional indirectness; N-CI:Nonconventional indirectness; BE:British English; $\mathrm{CH}$ :Chinese.

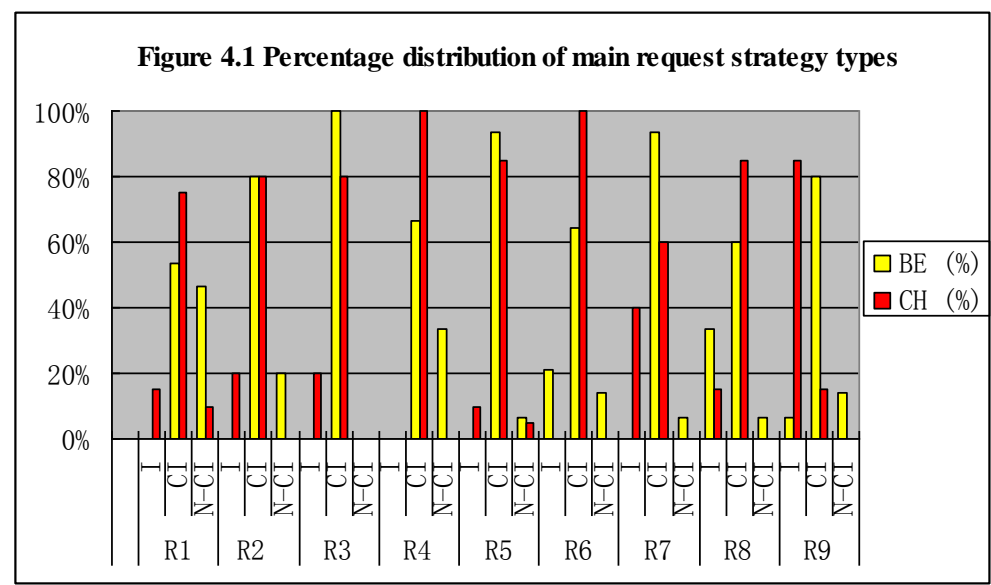

\section{A. Direct Strategies (Impositives)}

Figure 4.1 compares the use of impositives across the nine role-play situations in both languages. While this strategy follows a similar trend across most of the situations in both cultures, with Chinese showing higher levels of the strategy in some situations, and the proportion of impositives used within each situation varies.

This strategy was employed by Chinese in most of the situations, while the British found the use of the strategy appropriate mainly in situations 6 (ask a colleague to cancel his holiday) and 8 (ask an employee to help with a project), $18.75 \%$ and $31.25 \%$ respectively. In situation 9 (ask a colleague to treat you to a meal), only one person used this strategy. The common denominator in all the three situations is the fact that the interlocutors are familiar with each other or at least they are acquaintances, and the addressee's power was lower than the addresser. For example, in R6 (cancel holiday) the speaker has recently been granted higher status than the hearer having been put in charge of the execution of a high profile work project, a project for which s/he needs the co-operation of all members of staff, including the addressee who had booked a holiday. So, although the speaker and the hearer have equal status in that they have the same position at work, the speaker has gained institutionalized power, even if only temporarily. This institutionalized power would make it easier or shall we say less personal for the speaker to ask for such a high cost request, since in the mind of the participants the requester is the company and not the individual. 
The Chinese found this strategy more appropriate in R6 (ask someone to cancel his holiday), R7 (change jobs) and R9 (ask a colleague to treat you to a meal). Particularly in R9 the Chinese show a rather higher incidence than the British, $85 \%$ of the Chinese speakers used the obligation statement. In R7, the strategy was employed by $40 \%$ of the Chinese informants, and in R6, the number was more than $40 \%$.

In R9, the use of impositives seemed to be the most appropriate strategy in Chinese. Most Chinese participants used the obligation statement. For example:

“那你升职了得请我们大家吃顿饭啊。”

"Well, you have got a promotion, so you should treat us to a meal."

In R7, The preferred strategy of Chinese speakers was the mood derivable-imperative (40\%). This is the most direct request strategy in terms of head acts.

“嗯...那就麻烦您安排一下。”

"Yeah, please help, well, to arrange this among colleagues."

In R6, the strategies used by Chinese speakers are mood derivable and want statement. Such as :

“我看，你还是把假期往后延迟一下吧!”

“我希望你能把假期先放一放。”

The strategy was used across more situations in Chinese than in British English with varying proportions. It should be noted that the British employed the strategy in two types of situations: those in which the participants were familiar with each other - intimates-friends, friends and/or acquaintances — regardless of any status difference or degree of imposition as illustrated in R9 (ask a colleague to treat a meal) and in those situations where the speaker had higher status than the hearer as inR6 (cancel holiday) and R8 (ask an employee to help with a project).

It should be pointed out that the lowest incidence of the strategy is found in R4 (ask to stay in one's house), in which the participants have equal power, but they are familiar with each other, followed by R5 (ask a neighbor to help you move some things) in which the participants have equal power, and they are not familiar with each other, and a very low level in R1 (borrow money) where it is the hearer who has higher status than the speaker and the interlocutors are not friends. In these situations, the ranking of impositions are to the highest degree, and it would be hard for the speakers to ask the hearers to offer certain kinds of help, so it would be very impolite to use the direct strategy in English.

Thus, so far, it appears that the use of impositives in both cultures is motivated by interplay between social distance and social status without any considerations for the degree of imposition. It should also be noted that seven out of the nine situations where this strategy seem to be more appropriate are characterized by the fact that the participants know each other to varying degrees. The more familiar the participants are the more direct the strategy.

A further explanation for the use of impositives in these situations by speakers of both languages can be found in Ervin-Tripp's empirical research into the requesting behavior of Americans. The results of the research show that requests between family and friends tend to be more direct than those between strangers. Using Ervin-Tripp's finding we could hypothesize that the deference in the proportion of impositives used in those situations where the strategy was employed by both groups of informants, appears to show that the British see relationships with friends as more distant than their Chinese counterparts. There seems to be, still amongst close friends, an inclination to be seen as respecting the freedom of action of the hearer by not imposing upon him/her, in other words, an inclination for 'negative' politeness. On the other hand, the Chinese appear to see the distance between friends differently and show a higher degree of 'positive' politeness. Although there is also respect for the freedom of action of the hearer, as seen by the inter-play of the strategies employed, there is an assumed reciprocity between the participants. There is an implicit cultural 'guarantee' of no fear of loss of 'face' in requesting directly from a friend and/or close acquaintance. The commonly shared background information the speaker has about the hearer makes the use of impositives very appropriate and thus is the expected behavior, and vice versa. It could be said that by using impositives speakers show how committed they are to the belief that their addressees will comply with their requests, not because they will find them imposing but probably because of assumed cultural expectations of solidarity and reciprocity amongst friends (Ervin-Tripp, 1976, P.45).

\section{B. Conventional Indirectness}

As can be seen in Figure 4.1, conventional indirectness constitutes the most frequently used main strategy type in both cultures. Cross-cultural agreement on the appropriateness of the strategy is particularly salient in this strategy, this can be seen in the request R2 (borrow car), and in R8 (ask an employee to help with a project), the difference is less than $5 \%$.

Cross-cultural variation is obvious in R9 (ask a colleague to treat you to a meal), with a more than $60 \%$ difference in the use of the strategy between $\mathrm{CH}$ and BE. This is the biggest difference in all nine situations. In R9, almost $80 \%$ of the British tend to use the suggestory formula, such as, "How about treat us a meal?" While the Chinese preferred the use of impositives, which shows a more close relationship, as has been mentioned in the first part of this chapter. Less than $20 \%$ of the Chinese used this strategy.

A rather lower incidence of the strategy in both languages is found in R1(borrow money), $56.25 \%$ in $\mathrm{BE}$ and $75 \%$ in $\mathrm{CH}$, and in R6 (ask someone to cancel his holiday), 68.75\% in BE and 55\% in $\mathrm{CH}$, and its highest incidence is found in 
R3 (borrow one's laptop), with BE reaching their peak(100\%), and in R4(ask to stay in one's house ) and R6(ask someone to cancel his holiday), with $\mathrm{CH}$ reaching their peak( more than $80 \%$ ).

Conventional indirectness is dominant in more than half of the situations. According to Brown and Levinson, a speaker assesses the seriousness of a FTA according to the social distance, the social power between him/her and the addressee and the degree of imposition of the act. They claim that the less socially familiar the interlocutors are the more social power/status the hearer has over the speaker and the more imposition an act involves, the more indirect and thus polite the speaker will be. In R3 and R5, the interlocutors do not know each other very well, so there is a high incidence of this strategy. While in R4 (ask to stay in one's house) and R6 (ask someone to cancel his holiday), there is almost no status difference, and the interlocutors are familiar with each other. But the reason why there is still a high incidence of the strategy is that the weightiness of the request is rather high. Both the Chinese and the British find it's more appropriate to use the conventional-indirect strategy in order to be polite. And both the Chinese and the British tend to use the query preparatory in R4 and R6. The Chinese also used a lot of suggestory formula.

"Is it convenient for me to use your country house for a week?"

“你看, 方不方便把你在乡下的房子借我暂时住一下? ”

“䍐, 这次度假能不能暂缓一下?”

“你那个假期呢, 咱们能不能往后拖一拖? ”

“Can you postpone your holiday this time?”

The Chinese also used a lot of suggestory formula. For example,

“这次度假你就先别去了吧?”

But even if this had been the case, the degree of imposition does not seem, contrary to Brown and Levinson's theory, to be a significant variable affecting the informants' strategic choice. The variable that seems to be affecting this situation is social distance since as explained before--- there is a negative correlation between the variable and directness. Due to the fact that the participants are complete strangers and taking into account this negative correlation we would expect higher levels of indirectness. However, both groups of informants chose conventional indirectness instead of non-conventional indirectness. This linguistic behavior could be explained by the very same reason that makes us expect higher levels of indirectness: social distance. Let us not forget that the participants are strangers and that a non-conventional indirect request may not secure uptake under the circumstances, whereas a conventionally indirect one will not only make the compliance of the request appear as a free act but also secure the addressee's interpretation of the additional speaker's meaning. An impositive would not have been appropriate bearing in mind the status difference of the participants and the fact that the speaker is asking the addressee for a favor, and a nonconventionally indirect request could have been employed had the participants not been as familiar with each other.

\section{Non-conventional Indirectness}

As can be seen in Table 5 and Figure 4, non-conventional indirectness constitutes the least frequently used main strategy type in $\mathrm{CH}$, where it was only employed in two situations out of nine and with a very low incidence. The results of BE, however, are different. The strategy had a higher incidence than that of impositives though a lower incidence than $\mathrm{CI}$.

NCI was employed across eight situations with different degrees of incidence in BE. In British English the highest incidence of the strategy is found in R1, the request to borrow money followed by R4, the request to borrow a friend's house. There seems to be cross-cultural and situational agreement in the use of the strategy in R1, and in R5. However, the proportion of hints employed varies: in R1, BE employed $43.75 \%$ of NCI whereas Chinese speaker's usage of the strategy did not even reach half of that figure, $10.00 \%$. In R5 BE showed $6.25 \%$ against $5.00 \%$ of $\mathrm{CH}$. Although both groups of informants coincided in the choice of NCI in R1 and R5 there is some difference in the use of the strategy between $\mathrm{BE}$ and $\mathrm{CH}$.

The strategy was employed by Chinese only in R1 (the request to borrow money) and R5 (ask a neighbor to help you move some things with his/her car) with a very low incidence, ranging from $10.00 \%$ to $5.00 \%$. R1 and R5 are characterized by the common fact that the participants do not know each other well. A possible interpretation for the use of the strategy in R1 is the already discussed negative correlation between social distance and directness- the closer the speakers are the more direct the linguistic mapping of the request will be — as well as Brown and Levinson's fear of losing 'face' by having an 'on record' request denied.

In R1, the Chinese speaker has no choice but to borrow money from the recently appointed manager, because the speaker needs to pay the bills desperately, and the speaker already has a lot of debts. It is a rather awkward situation and makes the speaker feel embarrassed, so $10 \%$ of the participants choose to use the strategy of non-conventional indirectness, and most used the strategy of strong hint by stating the recent situation of being in need of money.

“我最近经济状况很紧张, 实在是没办法了...”

Let us look at the reason why the speaker used the strategy of non-conventional indirectness in R5, the speaker ask a neighbor to help move some things out of the flat. In this situation, the speaker troubled the hearer a lot, which will take him a lot of time. So this is a situation of high ranking of imposition. One out of fifteen Chinese participants used the strategy of strong hint.

“可是我没有车，这个时候也找不到其他人帮我......” 
In BE the strategy had a much higher incidence and it was used across eight situations except situation 3 . The highest incidence of the strategy is found in R1, the request to borrow money followed by R4, the request to borrow a friend's house. According to Brown and Levinson's understanding of 'off-record' requests, we would assume that the strategy of strong hint or mild hint was used in order to minimize the degree of imposition. Since in these situations, the degree of imposition is very high, the interlocutors are not familiar with each other, they must have strong motivation to choose the strategy. So it is logical to assume that by employing 'off-record' requests the speaker provides the addressee with the opportunity to volunteer. Therefore someone using a hint could either be leaving the options open to the addressee because they do not want to impose on him/her, or because they do not want to deprive the addressee of the pleasure of offering and indicating consideration for the speaker's needs. In fact, Brown and Gilman have suggested that 'offrecord' strategies mix with both 'positive' and 'negative' politeness strategies and they can be interpreted in different ways.

In R1 (borrow money) the participants are recent acquaintances. The hearer has higher status than the speaker who is an employee of the company. Hence it would be more appropriate to avoid uttering the request directly and only state the truth, since there is great possibility of being refused, and the speaker wants to avoid for fear of loss of 'face'. For example:

"I'm recently short of money. I've just rent a house and have a lot of bills to pay... I really don't know what to do..."

In R4 (ask to stay in one's house) the participants are friends and have the same status, the object of the request is high: the speaker wants the hearer to lend him/her their house. This situation yielded a variety of speech acts: requests by the speaker and by the hearer, invitations and offers by the hearer. In terms of the use of non-conventional indirectness, $31.25 \%$ in $\mathrm{BE}$ and $0 \%$ in $\mathrm{CH}$, it could be claimed it was used with one purpose of not imposing upon the addressee seeing the weight of the request and with another purpose of letting the addressee show his/her consideration for the speaker, in this case, a friend, by offering him/her the house. For example:

"Several relatives come to visit me. They will stay for about one week, but I don't have enough room in my own house. I've heard you have a vacant house here...."

In R6 (cancel holiday) the participants know each other well. The speaker has higher status than the hearer since s/he has been put in charge of a very important project at work and the weightiness of the request is very high since the hearer is asked to cancel his/her already booked holiday because of this project.

"This project is really important as well as urgent, and we just don't have enough hands..."

In R2 (borrow car) there is a slightly higher incidence of the strategy, probably due to the combination of a negative correlation between social distance and a positive one with social status. The participants have a friendly relationship, the speaker has less social status than the hearer and the weight of the request is very high. Thus the use of the strategy could either be interpreted as a non-imposition or as a solidarity seeking technique. For example:

"My car's just broken down. I've got half an hour to get to the airport to pick up my parents and I have no other means of transport. Can you help me at all?"

"Do you remember that big favor I did to you last year around Christmas, just before that... I just got this... to get to the airport and my car's broken down, you know any chance that you can just give me a hand?"

\section{CONCLUDING REMARKS}

By contrasting the strategies of head acts both in English and Chinese, we can find that the similarity between native Chinese speakers and native English speakers is that both value conventionally indirect strategies and their difference lies in that native Chinese speakers prefer to use direct strategies i.e. imperatives, in some cases, while native English speakers seldom choose to use imperatives when requesting someone to do something. Furthermore, in adopting conventionally indirect strategies, native Chinese speakers are inclined to use tag questions, such as “, ..., 好吗? /行 吗? /可以吗? / / 你同意吗? (...Is it ok? Do you agree?)”. While their English counterparts tend to use general questions in the forms of "Can/Could you...?", "Will/Would you...?" and "Would you mind...?"

In Chinese, direct strategies and conventionally indirect strategies complement each other. While in British English, conventionally indirect strategies are overwhelmingly preferred, with direct strategies only occupying a small portion. The reason of the difference of head acts in English and Chinese requests can also be traced back to their different cultural backgrounds in China and the English-speaking countries.

With respect to such an adoption of both the direct strategies and conventionally indirect strategies in Chinese, there are many reasons that we can find in the Chinese culture. In Chinese traditional culture, individual's position and power in the society is very much emphasized since China had been a hierarchical society for thousands of years. And because Chinese culture emphasizes collectivism in nature, the negative face, i.e. the need for freedom of action is not so stressed by Chinese people as by native English speakers. So to impose on someone's freedom of action does not usually threaten the addressee's face in Chinese. On the contrary, it is often acceptable in China. What really concerns the addressee's face in the Chinese society is his/her dignity or self-respect, and negative face does not exist in Chinese culture (Gu 1990:251).

All in all, Chinese requests stress both direct strategies - imperatives and conventionally indirect strategies - tag questions. These characteristics are the reflection of the traditional Chinese culture. Let us now turn to the cases in English. According to Blum-Kulka, native English speakers most often adopt the conventionally indirect strategies. 
They use direct strategies less frequently than Chinese people do. Bald imperatives will be considered as very rude among native English speakers. The preference of such request strategies by the native English speakers is also profoundly connected with the culture.

In almost all the English-speaking countries, individualism is highly valued and cherished. The value of equality is also emphasized in everything from government affairs to daily social deals. Since everyone in such a society treat others as equals, the power relationship, which is stressed in Chinese society, will not play a big role. As a result, direct strategies or imperatives, which seem more or less like orders, will certainly not be preferred when they make requests. Instead, what is considered more important is whether the addressee's freedom of action is interfered by the requests, thus native English speakers usually take the addressee's negative face into consideration. What is more, when requests are made, the politeness principles listed by Leech will always be observed then. That's to say, requesters will try to minimize the cost to others and not to impose.

The general questions such as "Can/Could you...?","Will/Would you...?" not only shows that the requester tries to get the permission of the addressee out of the consideration of his/her freedom of action but also indicates the equal relationship between them. Hence, such strategies will certainly be widely adopted by native English speakers.

\section{REFERENCES}

[1] Austin, J. L. (1962). How to Do Things with Words. Oxford: Oxford University Press.

[2] Brown, P. and S. Levinson. (1987). Politeness: Some Universals in Language Use. Cambridge: Cambridge University Press.

[3] Blum-Kulka, S. (1985). Modifiers as indicating devices: the case of requests. Theoretical Linguistics, 12 (2-3), 213-229.

[4] Blum-Kulka, S. and E. Olshtain. (1984). Requests and apologies: A cross-cultural study of speech act realization patterns. Applied Linguistics, 5,196-213.

[5] Edmonson, W. (1981). Spoken Discourse. London: Longman.

[6] Fukushima, S. (1996). Requests strategies in British English and Japanese. Language Sciences, 18, 671-688.

[7] Fukushima, S. (2003). Requests and Culture: Politeness in British English and Japanese. Bern: Peter Lang.

[8] Faerch, C. and G. Kasper. (1984). Internal and external modification in interlanguage request realisation. In Blum-Kulka, S., J.

[9] Gu, Y. (1990). Politeness phenomena in modern Chinese. Journal of Pragmatics. 14 (2), 237-257.

[10] Goffman, E. (1967). Interaction Ritual: Essays on Face-to-Face Behaviour. New York: Doubleday Anchor Books.

[11] House and G. Kasper. (eds.). Cross-Cultural Pragmatics: Requests and Apologies. Norwood NJ: Albex.

[12] Hong, W. (1998). Request Patterns in Chinese and German: A Cross-cultural Study. Munich: Lincom Europa.

[13] Lee-Wong, S.M. (2000). Politeness and Face in Chinese Culture: Cross Cultural Communication. Melbourne: Monash University Press.

[14] Leech, G. (1983). Principles of Pragmatics. London: Longman.

[15] Sifianou, M. (1992). The use of diminutives in expressing politeness: Modern Greek versus English. Journal of Pragmatics, 17 (22), 155-173.

[16] Trosborg, A. (1995). Interlanguage Pragmatics: Requests, Complaints and Apologies. Berlin: Mouton de Gruyter.

Xiuping Han, born in Binzhou, Shandong province, China, in 1980,12, with a master's degree in Literature (2010) from Ludong University, Yantai, Shandong Province. The major field of study is pragmatics.

She now works in BinZhou Medical College as an English teacher, with many papers concerning English language study and language teaching published. 